\title{
A simulation model to investigate impacts of facilitating quality data within organic fresh food supply chains
}

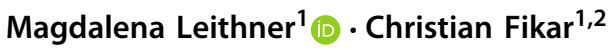

Published online: 8 November 2019

(c) The Author(s) 2019

\begin{abstract}
Demand for and production of organic fresh food play an increasing role worldwide. As a result, a growing amount of fresh fruits and vegetables has to be transported from predominantly rural production regions to customers mostly located in urban ones. Specific handling and storage conditions need to be respected along the entire supply chain to maintain high quality and product value. To support organic food logistics operations, this work investigates benefits of facilitating real-time product data along delivery and storage processes. By the development of a simulation-based decision support system, sustainable deliveries of organic food from farms to retail stores are investigated. Generic keeping quality models are integrated to observe impacts of varying storage temperatures on food quality and losses over time. Computational experiments study a regional supply chain of organic strawberries in Lower Austria and Vienna. Results indicate that the consideration of shelf life data in supply chain decisions allow one to reduce food losses and further enables shifting surplus inventory to alternative distribution channels.
\end{abstract}

Keywords Food logistics · Organic food · Simulation modeling · Decision support $\cdot$ Shelf life data

\section{Introduction}

Rising world population, ongoing urbanization and a shift to more fresh diets challenge the management of food supply chains (Parfitt et al. 2010; United Nations 2014). Particularly, demand for perishable goods like fresh fruits and vegetables (FFVs) grew markedly over

Magdalena Leithner

magdalena.leithner@boku.ac.at

Christian Fikar

christian.fikar@wu.ac.at

1 Institute of Production and Logistics, University of Natural Resources and Life Sciences, Vienna, Feistmantelstraße 4, 1180 Vienna, Austria

2 Institute for Production Management, WU Vienna University of Economics and Business, Welthandelsplatz 1, 1020 Vienna, Austria 
the past years (Reynolds et al. 2014). Supply chains for such perishable products differ significantly from non-edible ones as product qualities change over time and large sources of biological variance are present (Hertog et al. 2007). To ship perishable foods efficiently from rural production areas to consumers, mostly located in urban areas, and to avoid food and quality losses, supply chain management (SCM) has become an important concept in the fresh food industry (Jedermann et al. 2014; Parfitt et al. 2010). SCM plans, coordinates and controls logistics processes and tasks of the various actors to deliver commodities on time at competitive prices (Long and Zhang 2014; van der Vorst et al. 2009). Efficiently planned inventory management, stock rotation schemes as well as transportation and distribution are important for chain design and profitability (Soto-Silva et al. 2016).

Increased consumers' demand for fresh, safe and high quality foods and technological developments raise the importance of shelf life prediction (Giménez et al. 2012). In this context, the term 'keeping quality' describes the period, e.g., in days, during which a perishable product maintains its required quality attributes, i.e., the time until a product becomes unacceptable (Tijskens and Polderdijk 1996). The acceptability of a commodity depends on the required attributes which are defined by the visual appearance, like freshness and color, as well as texture, like firmness and juiciness (Ayala-Zavala et al. 2004). While the perception of growers, retailers and consumers influence the requirements on these attributes, specific storage temperatures and environmental conditions affect their state and behavior (Hertog et al. 2014; Nunes et al. 2014). If the remaining keeping quality is calculated at appropriate standard temperatures and conditions, it is further referred to 'shelf-life' (Tijskens and Polderdijk 1996). Environmental conditions like relative humidity, levels of oxygen and carbon dioxide in the surrounding air influence the quality of FFVs and lower shelf-life over time (Hertog et al. 2015; van der Vorst et al. 2009). Nevertheless, temperature is the most important factor influencing postharvest life of FFVs, dramatically affecting the rates of biological reactions and microbial growth (Li and Kader 1989).

Consequently, the duration of logistics operations and the environmental conditions along the entire supply chain should be considered in decisions along perishable supply chains (de Keizer et al. 2017). Quality controlled logistics enable the prediction of quality changes in each step in advance. Throughout chilled supply chains, various data are generated via sensors at various business partners which record time and temperature conditions the products are exposed to (Li and Wang 2017). Product quality and decay can also be controlled and tracked by technologies like time temperature indicators (TTI), radio-frequency identification (RFID) as well as refrigerated containers. This information can improve stock rotation systems enabling 'first expired-first out' policies (Jedermann et al. 2014). Additionally, food waste can be reduced by providing accurate estimations of the products' remaining shelf lives (Grunow and Piramuthu 2013) and products of different qualities can be used to serve different markets (van der Vorst et al. 2011). As a result, making supply chain decisions based on real-time data sets enables competitive advantages for food logistics providers (Zhong et al. 2016). Additionally, by incorporating such quality data and coordinating various decisions along the entire supply chain, sustainable operations can be supported. For instance, as FFVs commonly deteriorate quickly, inefficient supply chain processes lead to large amounts of food waste and losses (Lundqvist et al. 2008). Of the produced volume of FFVs in Europe, about $28 \%$ get lost along postharvest chains, i.e., during handling, processing, packaging, storage and distribution (Jedermann et al. 2014).

To support sustainable operations and investigate the impact of facilitating food quality data, this work presents a simulation-based decision support system (DSS). The focus is set on regional FFVs supply chains and on the impact of inventory and product assignment strategies. Food quality models are embedded in a discrete event simulation model to deal 
with the growing complexity and uncertainties occurring in regional FFVs supply chains. Consequently, the contribution of this work is twofold: (i) it presents a DSS to investigate a regional supply chain of perishables under the consideration of shelf life data, and (ii) provides managerial implications on how to incorporate such data to improve both food losses and operations. Preliminary results and selected experiments of this work were published in Leithner and Fikar (2018).

The remainder of this work is structured as follows: Sect. 2 introduces related literature. The individual components of the developed DSS are introduced in Sect. 3. Computational experiments based on a regional organic strawberry supply chain in Lower Austria and Vienna are described in Sect. 4. Results are presented and discussed in Sect. 5 and concluding remarks given in Sect. 6.

\section{Related work}

Operations research (OR) methods present powerful tools to handle uncertainties and the complexity of food logistics operations (Borodin et al. 2016). Potential sources of uncertainty include seasonable varying demand and supply, varying harvest times, unpredictable weather conditions as well as a limited and changing shelf-life (Ahumada and Villalobos 2009; Fredriksson and Liljestrand 2015; Khorshidi et al. 2010). Nevertheless, these factors complicate the integration and adaption of decision support systems (DSSs) within the FFVs industry (Rong et al. 2011; Soto-Silva et al. 2016). Consequently, OR methods still find limited application to improve decisions along postharvest chains (Higgins et al. 2010).

Ahumada and Villalobos (2009) review planning models in agricultural supply chains. The authors classify agricultural supply chains into two main types: (i) fresh agri-foods like fruits and vegetables with a short shelf-life expressed in days and (ii) non-perishable agri-foods that can be stored for a longer period of time like potatoes, grains and nuts. The interest on fresh products is emphasized due to their logistical complexity, short shelf-life and public interest on the safety of these products. Nevertheless, they assert that planning models applied to perishable products often fail to include realistic stochastic and shelf-life features. Additionally, Soto-Silva et al. (2016) analyzed literature of the last decades dealing with OR models applied to the fresh fruit supply chain. Linear programming is the predominant modeling technique. The objective function mostly tries to maximize profit, net present value or net revenue by focusing on various processes like production (14 articles), harvesting (12), distribution (12), inventory management (6) and planting (4). The authors conclude that a new generation of decision technologies is needed which integrate variables like quality deterioration and wastage to enable holistic approaches for redesigning and managing fresh food supply chains.

Consequently, DSSs which are able to cope with the special characteristics of FFVs are required to support decision making processes within food supply chain management. In this context, particularly Big data analytics is gaining importance as the access to sensor technologies and satellite information is getting cheaper (Cancela et al. 2019). An interface called 'AgroDSS' between agricultural systems and decision support methodologies is presented in Rupnik et al. (2019). The developed methodology is intended to be integrated in existing farm management information systems and provides various data analysis methods to support decisions. Focussing on fresh apples, Soto-Silva et al. (2017) developed an optimization model to improve purchasing, transporting and storing by considering parameters like purchasing costs, producer administration costs, transport costs and storage capacity. Raut 
et al. (2019) present a multi criteria decision making approach to avoid food losses caused by cold third-party logistics provider evaluation and selection processes. Results indicate that the cooling capacities and infrastructure as well as the loading processes and the knowledge and information technology management are key factors in regard of reducing food losses.

Simulation models, due to the ability to consider risks and uncertainties occurring in fresh food supply chains and their inherent modeling flexibility, are commonly used within DSSs investigating food supply chains (van der Vorst et al. 2009; Long and Zhang 2014). Furthermore, simulations facilitate the comparison of performances under varying conditions (Long and Zhang 2014; Tako and Robinson 2012). A tactical decision support model to improve the effectiveness of operations within a distribution center dealing with FFVs is introduced in Broekmeulen (1998). Based on historical data, the model determines an assignment plan for storage advice and checks its impacts on quality losses. van der Vorst et al. (2009) define a food supply chain as a netchain where various actors (growers, auctions, importers and exporters, retailers and specialty shops and their logistics service providers) are responsible to bring produces from producers to customers. Handling, stocking, packaging and distribution are the main processes within the discrete event simulation framework which influence the intrinsic characteristics of the products grown or produced. The impact of varying inventory strategies and incorporating dynamic food quality data at various stages of the supply chain is not explicitly considered. Fikar (2018) presents a DSS focusing on the distribution of FFVs in e-grocery operations, i.e., the shipment of food products to customer premises. An agent-based simulation is developed integrating both food quality and vehicle routing models. Results highlight the importance of integrated routing and inventory strategies to reduce food losses.

Additionally, various authors developed models to simulate and calculate the changes of quality occurring in perishable products. Sloof et al. (1996) state that quality changes can be formalized with a quality change model subdivided into three sub-models describing the quality assignment, the physiological behavior of the products and the changing environment. Tijskens and Polderdijk (1996) present a model that considers the effects of time and temperature on quality of several FFVs. Such changes in quality are calculated by considering product acceptability, the biological quality reaction rate and environmental conditions. The model was extended by Hertog and Tijskens (1998) considering the effects of $\mathrm{O}_{2}$ and $\mathrm{CO}_{2}$. In Nunes et al. (2014), the predictive microbiology approach models the growth of spoilage microorganisms displaying the typical sigmoidal appearance of bacterial growth of minimally processed foods as a function of food characteristics like salt concentration and $\mathrm{pH}$, temperature and time (Corbo et al. 2006). Another way to predict the shelf-life of perishable products is to observe the respiration rate of FFVs (Nunes et al. 2014). Single quality factor models assume changes of a specified quality attribute representing biological reactions like changes in color of tomatoes (Hertog et al. 2004), shriveling of apples (Hertog 2002) and changes in soluble solids (Díaz-Pérez et al. 2003; Nunes et al. 2014). While this approach is able to effectively predict the shelf life of some FFVs, the monitored factor must be shelf-life limiting to maintain realistic results (Nunes et al. 2014). In contrast, multiple quality factor models consider that some quality attributes are more critical than others (Nunes et al. 2014). Additionally, various related work focuses on the development of technologies for remote monitoring of environmental conditions along food transportation and storage. For a review of trends in remote cold chain monitoring technologies and temperature estimation methods, refer to Badia-Melis et al. (2018). 


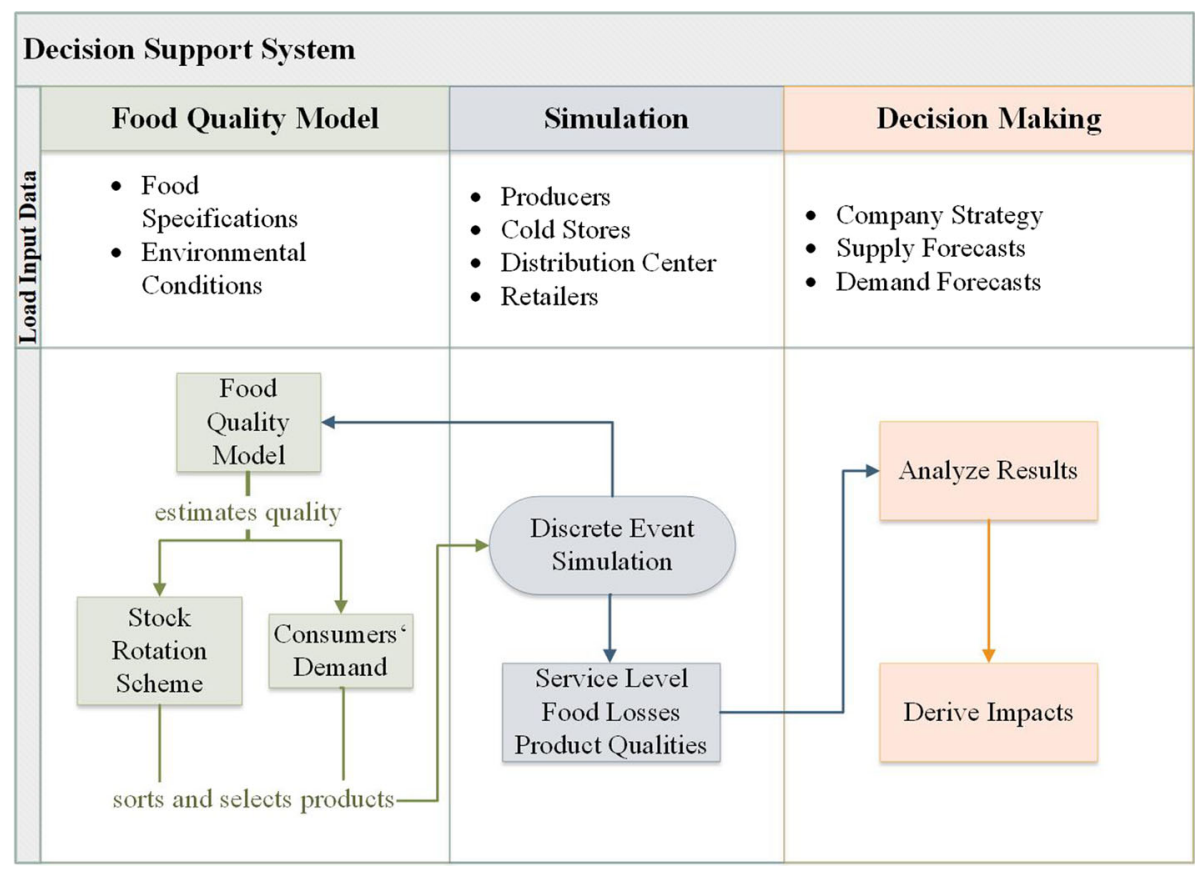

Fig. 1 A DSS to facilitate quality data in organic fresh food supply chains

\section{Decision support system}

To investigate organic food distribution throughout multiple weeks of operations, a DSS was developed, as displayed in Fig. 1. The developed system provides decision support to farmers, operators of distribution centers and retailers. By integrating quality data, it states which products should be selected for shipment and which ones may be sold via alternative distribution channels. The core of the system is a discrete event simulation, which models the supply chain with uncertainty present in both supply and demand. The generic keeping quality model presented in Tijskens and Polderdijk (1996) is integrated to model quality changes and handle data concerning storage temperatures and durations resulting from the performed logistics decisions.

The investigated supply chain structure is introduced in Fig. 2. The DSS is initialized with producers, cold stores, distribution centers and retail locations within the study region, each indicated by geographic latitude and longitude and matched to the closest street segment. It is assumed that each producer has a cold store, where the harvested goods are stored until they are delivered to a central distribution center. The distribution center stores all incoming products and distributes the products to retail stores, where customers meet their demand. Producers and the distribution center independently operate multiple trucks for delivery processes. Each location (field, cold store, distribution center, retail store) as well as trucks have specified storage temperatures. Additionally, production and demand forecasts as well as product specifications need to be defined to initialize the system.

An overview of the modeled process is given in Fig. 3. It models the flow of a product from harvest at a field to its final usage, i.e., the product is either lost, moved to an alternative 


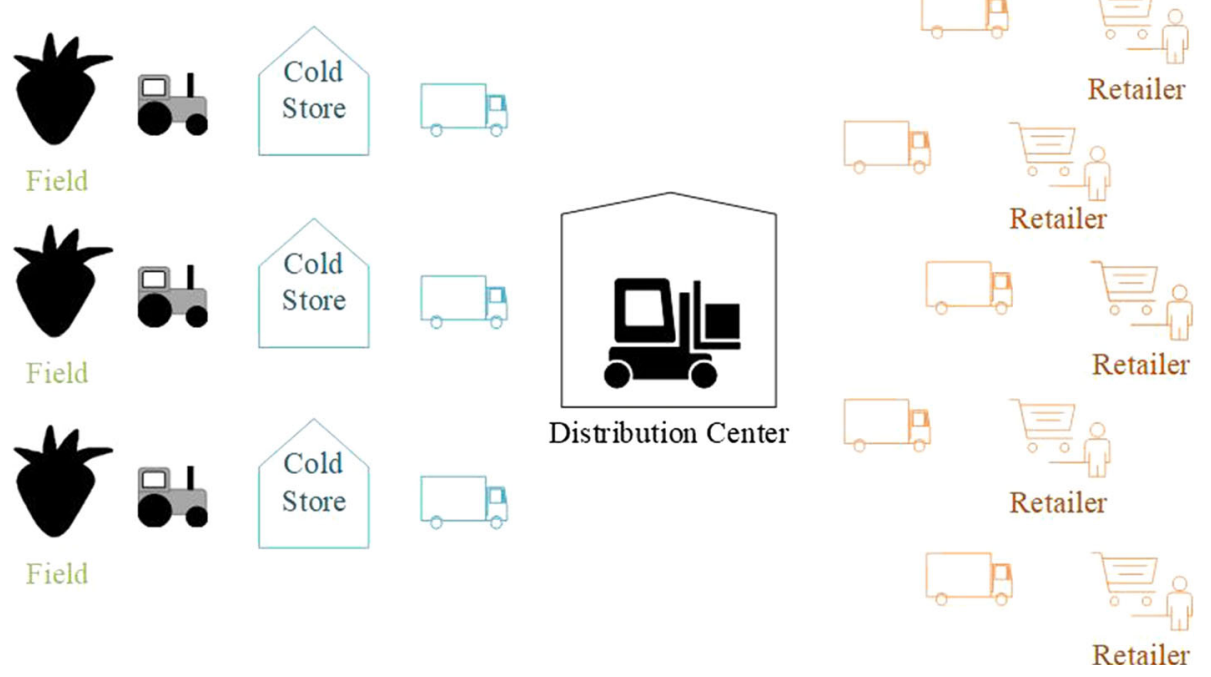

Fig. 2 Modeled fresh fruit supply chain structure

distribution channel or sold. The individual components of the simulation model are described in detail in the subsequent subsections.

\subsection{Field}

The supply chain starts at the producers' fields. The harvest process is limited to a user defined time period per day and based on a specified arrival rate. The picked produces are prepackaged to consumer batches and defined by an initial quality. According to a uniform distribution, this initial quality varies between a predefined range to model biological variance present in harvest operations. From the point of harvest, the quality of each batch starts to deteriorate, depending on storage and handling temperatures and durations along the supply chain. Therefore, a quality limit is determined by the user and if the quality drops below this limit, the product is removed from the process and counted as food loss.

In each process step, the time the perishable item goes through this process flow is measured. After a change in temperature, quality is updated according to the generic keeping quality model presented in Tijskens and Polderdijk (1996). Quality changes are reproduced with zero order reaction kinetics. For calculations of the changes in quality, Eq. (1) is applied. The variable $k_{i}$ describes the spoilage rate of the perishable product at a specific temperature, i.e., by how much the shelf life is shortened, which is depending on the absolute temperature $T_{a b s}$ as described by Arrhenius' law (Laidler 1984). During one process flow, $k_{i}$ is subtracted for the duration $t$ from the current quality $Q_{s}$ before entering the subsequent process flow, resulting in the updated quality $Q_{s+t}$.

$$
Q_{s+t}=Q_{s}-k_{i} t
$$

Within the simulation, the batches are loaded to an unchilled collection vehicle on the field and are transported to a cooling facility once the harvest process is finished. 


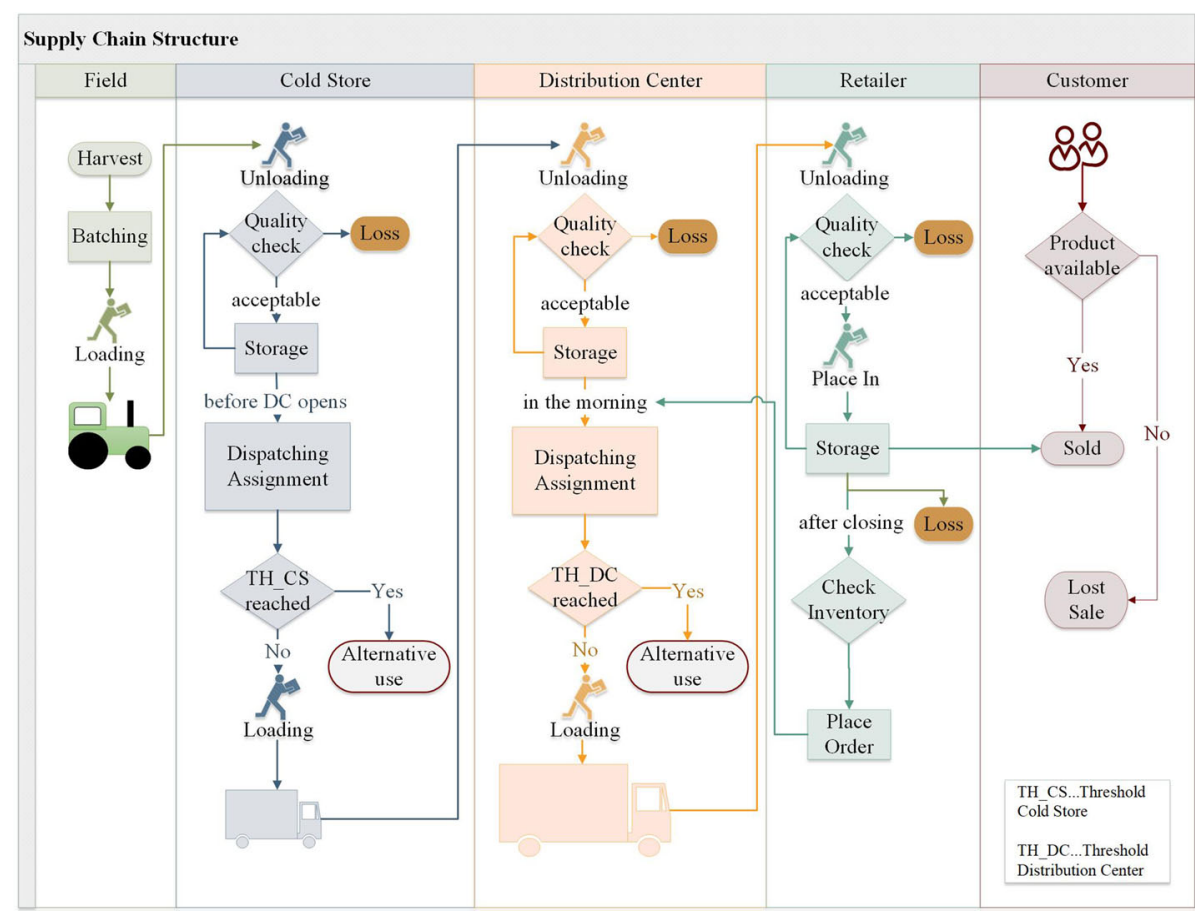

Fig. 3 Process flow chart integrated within the DSS

\subsection{Cold store}

At arrival at the cold store, the products get unloaded and stored in a chilled area. Considering opening time windows of the distribution center, delivery schedules are set. At each delivery, the farmer needs to decide which products are shipped to the distribution center. Therefore, a quality threshold is set. Products with a current quality at loading above this limit get loaded on chilled trucks for transportation, while the remaining products exit the process and are assumed to be sold directly or used for related tasks such as juice or jam production.

\subsection{Distribution center}

The distribution center has defined opening hours for incoming deliveries of produces and is assumed to have sufficient space for all goods. At arrival of an incoming truck from the cold store, qualities are updated and checked against the minimum contracted threshold quality. Incoming orders from retailers are fulfilled according to a user-defined weekly delivery schedule. The quantity of produces ordered by the different retail stores on a given day is defined by the selected replenishment strategy of the retailer, which is discussed in the subsequent Sect. 3.4.

For fulfillment, the distribution center has to decide which specific products to ship on a given day. Similar to the cold store operations, a threshold quality is again implemented to decide at which time products are removed from the warehouse storage and used for alternative distribution channels. The assignment of products to retailers is performed in two 
First Expired - First Out

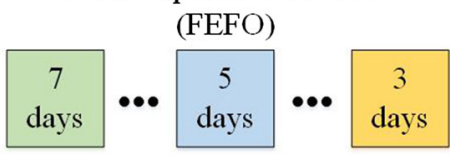

Last Expired - First Out
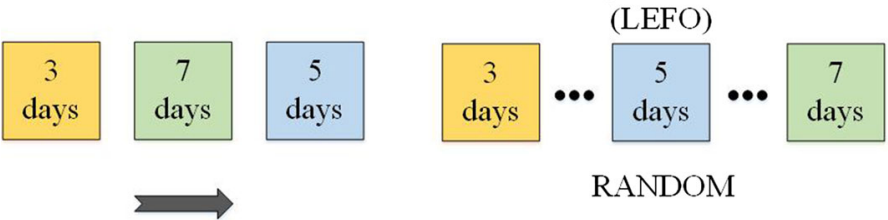

RANDOM

incoming produces

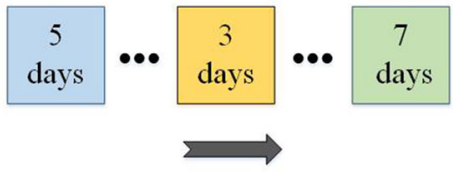

outgoing produces sorted

Fig. 4 Inventory strategy

steps. The first step selects all products to be shipped on a given day, i.e., the total amount of produces ordered by all retailers. Therefore, various stock rotation schemes, shown in Fig. 4, are implemented. "First expired-first out (FEFO)" and "last expired-first out (LEFO)" consider real-time product quality data, i.e., the products with the shortest shelf lives are shipped first or last, respectively. Therefore, the quality of all stored products is recalculated within the DSS each time goods are selected for delivery. A random stock rotation scheme is additionally implemented to investigate the impact of no food quality data available.

The second step assigns the selected products, which are sorted by the specific stock rotation schemes, to individual retail stores, i.e., orders. Following the recommendation derived in Jedermann et al. (2014), the assignment is based on the respective demand of the individual stores. Consequently, retailers with large order sizes such as discount stores are assigned products first. In contrast, premium locations where only few items are purchased, receive lower ranked produces. Within the DSS, a round robin selection process is implemented in which the retailer with the largest order size is assigned the highest ranked product. This product is removed from the ranking and the retailer's remaining order size is reduced by one. This procedure is repeated until all products are assigned to orders. At this point, goods are loaded to trucks and shipped to the retail stores.

\subsection{Retail store and customer}

At arrival of a truck to a retail store, products are unloaded and the quality is checked against the contracted minimum quality. During storage, the quality of products is updated each time demand occurs and unacceptable goods are removed from the inventory and counted as food loss. Three different store types are implemented within the DSS: (i) gourmet stores with low demand; (ii) regular stores with medium demand; and, (iii) discount stores with high demand. Demand is simulated according to a Poisson-distributed arrival rate of customers during the opening hours of stores. At each arrival, the customer aims to purchase one batch of products. If goods are available, the specific product is selected based on a user defined 
demand priority. The customer either always buys (i) the product with the lowest remaining quality (FEFO), (ii) the highest quality (LEFO) or (iii) a random one. If there are no goods available, the customer's demand is lost and counted as a lost sale.

For replenishment of products, a single-product and stochastic inventory control problem of a perishable product is considered. Before each replenishment, the quality of unsold products in the stores is rechecked and unacceptable products are removed. Based on the remaining inventory level of acceptable goods, orders are placed. Therefore, the following five policies, as described in Haijema and Minner (2016), are implemented: COP, BSP, s,S policy, COPsQ and SQmax. The constant order policy (COP) always orders the same amount of goods at a periodic review moment, while the base stock policy (BSP) places an order at a periodic review point that brings the inventory position back to the predefined base stock level. In contrast, with the s,S or COPsQ policy, only if the inventory level of acceptable goods is below a predefined reorder point at a periodic review moment, an order is placed. The order quantity is either constant (COPsQ) or based on the base stock level (s,S). The final policy, SQmax, extends BSP by further introducing a maximum order quantity to reduce the risk of outdating.

\section{The case of strawberries in Lower Austria}

The model was developed to investigate a regional supply chain of organic strawberries in Lower Austria and Vienna based on a project collaboration with Bio Austria, the association of Austrian organic farmers (Bio Austria 2018b). Within Austria, 65\% of produced strawberries are sold via food retailing while $6.7 \%$ are sold directly and $3.9 \%$ to the processing industry with the remaining share of more than $20 \%$ being wasted (Schneider et al. 2014). The cultivated area where organic strawberries are produced substantially increased within Austria over the last decades with more than 58\% of Austrian organic strawberry production located in the investigated study area (Bio Austria 2018a).

Production and demand data are loaded into the model as well as quality data of strawberries and considered temperatures. Due to confidentiality reasons, the specific locations of providers have been abstracted to a district level in this study. 59 organic farmers, one distribution center in Lower Austria and 359 retail stores of a major Austrian grocery chain are implemented in the DSS. Due to lacking data on consumption volumes of organic strawberries, consumption data of conventionally produced ones are taken to approximate demand. A market share of $8 \%$ of organic strawberries in food retailing is assumed (BMNT 2016).

Based on the production area of organic strawberry farmers in Lower Austria (35 ha) and Vienna (16 ha), a total production volume of $1,224,000$ batches per year is calculated assuming a yield of $12,000 \mathrm{~kg} / \mathrm{ha}$ and a batch size of $0.5 \mathrm{~kg}$. By further considering 90 days of harvest season and that $65 \%$ of strawberries are sold via retail, this leads to an expected production volume of 8,840 batches per day for retail operations. Demand of organic strawberries in Lower Austria and Vienna is based on the per capita consumption of strawberries per year $(3.3 \mathrm{~kg}$ ) multiplied by the self-supply percentage (41\%) for strawberries of Austria (Statistik Austria 2017). This is further multiplied by the population size of Lower Austria and Vienna $(3,328,920)$ (Statistik Austria 2013) and an organic market share of 8\% (BMNT 2016). Again assuming a harvest season of 90 days and a batch size of $0.5 \mathrm{~kg}$, this results in 8,007 batches demanded daily. Consequently, supply slightly exceeds demand by about $10 \%$ in the investigated problem setting. 
For replenishment of retail stores, the BSP policy is selected assuming a desired fill rate of $95 \%$. With the exception of Sundays, orders are placed daily with the order quantity being set based on the difference between the current stock level and the desired base stock. All data is modeled as parameters within the simulation model and, consequently, can be easily adjusted by the user if additional data is available or varying problem settings need to be investigated.

\subsection{Food quality models tailored to strawberries}

Assuming spoilage as one of the most limiting factors regarding the physiology of strawberries, quality decreases are modeled using the spoilage rate parameter $k_{i}$ described in Equation (1). Dealing with strawberries, the quality can be assessed as a batch keeping quality, which describes the percentage of strawberries infected with spoilage within one single batch (Schouten et al. 2002). Hertog et al. (1999) and Schouten et al. (2002) consider different batch sizes and measured their initial quality, which displays a slight infection of spoilage. These values are subtracted from $100 \%$ (best quality) to display the initial qualities, immediately after picking. An initial quality between the given values in Table 1 is uniformly assigned to each harvested batch. In Eq. (2), the calculation of $k_{i}$, the spoilage rate of a strawberry batch, is displayed. $k_{r e f}$ represents the spoilage rate of one strawberry batch at reference temperature $T_{r e f}$ as described by Arrhenius' law (Laidler 1984). Considering a constant activation energy $E_{a}$, gas constant $R$ and the changing absolute temperatures $T_{a b s}$ of each process step, $k_{i}$ changes according to the absolute temperature, i.e., higher temperatures accelerate the deterioration process while low ones delay it.

$$
k_{i}=k_{r e f} e^{\frac{E_{a}}{R}\left(\frac{1}{T_{\text {ref }}}-\frac{1}{T_{a b s}}\right)}
$$

To calculate the remaining shelf life of strawberry batches in days, the quality limit $Q_{l i m}$ is subtracted from the current quality $Q_{s}$ and divided by the spoilage rate at reference temperature $k_{r e f}$, as shown in Eq. (3). The quality limit is set to $95 \%$ representing the time until one strawberry within one batch of 20 strawberries rots. In order to consider customer satisfaction, the minimum threshold quality along the supply chain is set to a remaining shelf life of two days at reference temperature, i.e., each strawberry with a remaining shelf life of less than two days is counted as food loss within the study.

$$
K Q_{r e f}=\frac{Q_{s}-Q_{l i m}}{k_{r e f}}
$$

Table 2 lists the considered temperatures in reference to related literature. Six different temperature zones are incorporated in this case study. As strawberries are harvested between May and July, high temperatures occur on the fields $\left(23.9^{\circ} \mathrm{C}\right)$. Afterwards, the strawberries are stored in chilled storage with a controlled temperature of $3{ }^{\circ} \mathrm{C}$ (cold storage at producers' places and within distribution centers). Transports are chilled as well, assuming the same temperature of $3^{\circ} \mathrm{C}$. Opened storage doors of vehicles, to pick out food during deliveries, decrease the quality of the remaining products in the vehicles (Song and Ko 2016). Consequently, in our work, temperatures during unloading and loading operations differ from transport temperatures and are set to $10^{\circ} \mathrm{C}$ affecting all loaded items. 
Table 1 Parameters for modeling food quality of strawberries. Data based on Schouten et al. (2002)

\begin{tabular}{llll}
\hline Parameter & Variable & Value & Dimension \\
\hline Gas constant & $R$ & 8.314 & $\mathrm{~J} \mathrm{~mol}^{-1} \mathrm{~K}^{-1}$ \\
Reference temperature $\left(10^{\circ} \mathrm{C}\right)$ & $T_{\text {ref }}$ & 283.15 & $\mathrm{~K}$ \\
Spoilage rate at reference temperature & $k_{\text {ref }}$ & 0.5009 & day $^{-1}$ \\
Activation energy & $E_{a}$ & 68,811 & $\mathrm{~J} \mathrm{~mol}^{-1}$ \\
Initial quality & $Q_{0}$ & $99.141-99.902$ & $\%$ \\
\hline
\end{tabular}

Table 2 Temperatures $\left({ }^{\circ} \mathrm{C}\right)$ along supply chains for fresh berries

\begin{tabular}{llllr}
\hline Location & Strawberries $^{\mathrm{a}}$ & Blackberries $^{\mathrm{b}}$ & Strawberries $^{\mathrm{c}}$ & This work \\
\hline Field & - & 23.9 & - & 23.9 \\
Producer/coldstore & 12.0 & - & 3.0 & 3.0 \\
Distribution center & 4.0 & 1.1 & 3.0 & 3.0 \\
Transport & 10.0 & $0.6-1.7$ & 3.0 & 3.0 \\
Loading/unloading & - & - & - & 10.0 \\
Retail store & 16.0 & 6.7 & 20.0 & 20.0 \\
\hline
\end{tabular}

${ }^{a}$ Hertog et al. (1999); value for distribution center taken from temperature at auction

b Nunes et al. (2014)

${ }^{\mathrm{c}}$ Nunes and Emond (2003)

\subsection{Design of experiments}

The DSS was developed using the simulation software AnyLogic 8.2.3 (AnyLogic 2018). Input data are loaded from a database connected to the DSS. During a single simulation run, truck movements and various statistics, e.g., current food quality and food losses are visualized. After each simulation run, the average fill rate of all retailers, the amount of food losses, the number of strawberries sold and the average quality of berries at purchase are reported. Multiple runs with varying input parameters and stochastic factors are done. Afterwards, the aggregated results are analyzed to identify the impacts of these parameters on supply chain performance. The implemented parameters are listed in Table 3 , representing the values of the base scenario in the computational experiments. The values in the variation column state the maximum and minimum values of the parameter as well as the steps the parameters are varied.

Figure 5 presents the simulation horizon. Each run starts on 1 May 2017. In order to enable a fair comparison of multiple varying simulation runs, a warm up, a reference and a cool down period are set. Based on extensive computational experiments, the first eight weeks of the simulation act as a warm-up phase. During this period, the system is initialized to reach a steady-state and no statistics are collected to avoid distorted results. The subsequent four weeks are selected as the reference period in which all harvested strawberries are tracked, representing approximately 248,000 products per simulation run. Once the reference period is over, a cool-down period is started to enable all reference strawberries to reach their final destination before the simulation ends. During this cool down period, additional strawberries are harvested, however, not counted to the statistics. Once all strawberries harvested within the reference period leave the system, i.e., are either lost, sold or moved to alternative distribution 
Table 3 Parameters of the computational experiment

\begin{tabular}{|c|c|c|c|}
\hline Group & Parameter & Base scenario & Variation \\
\hline \multirow[t]{3}{*}{ Simulation } & replications & 25 & \\
\hline & warmUpPeriodInWeeks & 8 & \\
\hline & referencePeriodInWeeks & 4 & \\
\hline \multirow[t]{3}{*}{ Supply } & harvestTimePerDayInHours & 2 & \\
\hline & totalSupplyPerDayInBatches & 8840 & \\
\hline & supplyVariation & 0.1 & \\
\hline \multirow[t]{5}{*}{ Demand } & totalDemandPerDayInBatches & 8007 & \\
\hline & demandVariation & 0.1 & \\
\hline & leadTimeInDays & 0 & \\
\hline & stdLeadTimeInDays & 0 & \\
\hline & fillRateTargetInPercent & 95 & \\
\hline \multirow[t]{2}{*}{ Transport } & speedOfTrucksInKmh & 80 & \\
\hline & timeLoadingAndUnloadingInMin & 15 & \\
\hline \multirow[t]{3}{*}{ Strategies } & replenishmentStrategy & BSP & \\
\hline & stockRotationSystem $^{\mathrm{a}}$ & 1 & $\{1,2,3\}$ \\
\hline & customerRequirements $^{\mathrm{a}}$ & 1 & $\{1,2,3\}$ \\
\hline \multirow[t]{2}{*}{ Threshold } & Cold Store & 98.652 & $\{98.652,98.702, \ldots, 99.652\}$ \\
\hline & Distribution Center & 96.002 & $\{96.002,96.052, \ldots, 99.002\}$ \\
\hline
\end{tabular}

a $1 \ldots$ FEFO, 2 ...LEFO, 3 ...Random

\begin{tabular}{|c|c|c|}
\hline \multicolumn{3}{|c|}{ Simulation Horizon } \\
\hline Warm Up & Reference Period & Cool Down \\
\hline \multicolumn{3}{|l|}{ Start Harvest } \\
\hline \multirow[b]{2}{*}{8 weeks } & Reference Strawberries & \\
\hline & 4 weeks & $\sim 1-2$ weeks \\
\hline $\begin{array}{l}\text { Start } \\
\text { Simulation 01.05.2017 }\end{array}$ & & $\begin{array}{r}\text { End } \\
\text { Simulation }\end{array}$ \\
\hline
\end{tabular}

Fig. 5 Simulation horizon

channels, the simulation stops and results are reported to the user. To consider stochasticity, each experiment is replicated 25 times, i.e., reported results represent data from 100 weeks of strawberry operations for each individual parameter setting. Detailed results and all absolute values of each replication are available online at http://short.boku.ac.at/instances.

The harvest process lasts two hours each day from 6 a.m. to 8 a.m. To simulate uncertainties in supply, the harvest rate of each producer follows a triangular distribution, where the minimum and maximum value are $-/+10 \%$ of the total amount of strawberries produced each day divided by the amount of producers. The distribution center accepts goods from producers at $8 \mathrm{p} . \mathrm{m}$. and delivers the goods to the retail stores starting at $6 \mathrm{a} . \mathrm{m}$. The products are delivered to retail stores in the morning hours from Monday to Saturday. Demand is restricted to the opening hours of stores, which are set from 7:30 a.m. to 8 p.m. from Monday to Friday and from 7:30 a.m. to 6 p.m. on Saturday. All unloading and loading processes last 
15 minutes and the average speed of trucks is assumed to be $80 \mathrm{~km} / \mathrm{h}$. Travel distances are automatically calculated based on integrated OpenStreetMap data (OpenStreetMap 2018).

Customer demand can differ substantially based on the specific store type with discounters commonly experiencing the highest demand and smaller stores lower ones (Teller et al. 2018). Therefore, within the experiments, demand is split into three store categories: gourmet, regular and discount stores. Of all considered stores within the study area, $8.64 \%$ of retail stores are classified as gourmet stores, $71.03 \%$ as regular stores and $20.33 \%$ as discount stores. Regular demand is calculated as the total number of strawberry batches divided by the amount of retailers. Mean demand at gourmet stores and discount stores is assumed to be $60 \%$ and $120 \%$ of regular demand, respectively. A quality limit of $96.002 \%$ is implemented indicating that goods with less than two days remaining shelf life at reference temperature are rejected from the process and counted as food loss.

The performed computational experiments investigate the impact of varying stock rotation systems, different customer requirements and implementing minimum quality thresholds at cold stores and the distribution center. Results focus on the number of strawberries sold, lost and moved to a different distribution channel throughout the simulation horizon to evaluate benefits of integrating quality data.

\subsection{Assumptions and limitations}

Only ripe fruits suitable for human consumption are considered in this work. Unripe, overripe or unacceptable fruits which do not conform market standards do not enter the process flow. All regarded products are distributed via the distribution center, which takes all incoming products and has no storage restrictions. Every producer has the ability to store the strawberries in a chilled environment within our study. It is assumed that transports from the distribution center to the retail stores are not limited to strawberries, but that these products are shipped with other perishable items, which require the same transport conditions. Quality changes are reproduced with zero order reaction kinetics as, for reasons of comparison, the type of kinetic mechanism of quality decrease is insignificant. All considered produces are sold via retail stores with stores representing the pertinent demand of Lower Austria and Vienna.

\section{Results and discussion}

For the base scenario, the impact of implementing the three considered stock rotation schemes in combination with the different customer demand priorities are analyzed. Results are shown in Table 4. The FEFO stock rotation scheme in combination with the FEFO demand priority of customers performs best regarding the amount of reference strawberries sold and lost. As in such a setting the lowest quality is always prioritized, goods are stored for shorter periods, i.e., less quality is lost and more goods can be sold. Overall, the FEFO approach reduces food losses, however, all goods are rejected at the retail stores and, independent of the customers demand priority, no losses occur at the distribution center. Such food losses occur at the distribution center if a LEFO stock rotation scheme is implemented, particularly when customers prioritize lower quality products. If customers prioritize high quality, the LEFO stock rotation scheme performs similar to the FEFO one. In the case that no real-time quality data is available, i.e., the customers choose randomly and the distribution center does not consider quality data either, slightly more goods get lost at the retailer than at the distribution 
Table 4 Impact of stock rotation schemes and demand priority for the base scenario

\begin{tabular}{|c|c|c|c|}
\hline \multirow[t]{2}{*}{ Stock rotation } & \multicolumn{3}{|c|}{ Demand priority } \\
\hline & FEFO & LEFO & RANDOM \\
\hline \multicolumn{4}{|l|}{$F E F O$} \\
\hline$\%$ Sold $^{\mathrm{a}}$ & 90.89 & 88.68 & 89.97 \\
\hline$\%$ TH_DC ${ }^{b}$ & 0.00 & 0.00 & 0.00 \\
\hline$\% \mathrm{FL}_{-} \mathrm{RT}^{\mathrm{c}}$ & 9.11 & 11.32 & 10.03 \\
\hline Av. quality sold (in days) & 4.26 & 6.02 & 5.14 \\
\hline \multicolumn{4}{|l|}{$\angle E F O$} \\
\hline$\%$ Sold $^{\mathrm{a}}$ & 88.14 & 88.25 & 88.30 \\
\hline$\%$ TH_DC ${ }^{b}$ & 8.49 & 1.66 & 5.66 \\
\hline$\% \mathrm{FL}_{-} \mathrm{RT}^{\mathrm{c}}$ & 3.38 & 10.09 & 6.03 \\
\hline Av. quality sold (in days) & 6.59 & 7.06 & 6.79 \\
\hline \multicolumn{4}{|l|}{ RANDOM } \\
\hline$\%$ Sold $^{\mathrm{a}}$ & 88.18 & 88.09 & 88.33 \\
\hline$\%$ TH_DC ${ }^{b}$ & 8.59 & 2.41 & 5.56 \\
\hline$\% \mathrm{FL}_{-} \mathrm{RT}^{\mathrm{c}}$ & 3.23 & 9.51 & 6.11 \\
\hline Av. quality sold (in days) & 6.38 & 6.97 & 6.66 \\
\hline
\end{tabular}

a $\%$ of reference strawberries sold at retailers

$\mathrm{b}_{\%}$ of reference strawberries lost at distribution centers

$\mathrm{c}_{\%}$ of reference strawberries lost at retailers

center. Highest qualities can be offered to customers if LEFO stock rotation is implemented. Random stock rotation gains marginally lower qualities whereas the FEFO stock rotation reduced the remaining shelf life at customers significantly. Depending on demand priority and compared to the random stock rotation, shelf life is shorten by more than two days with FEFO, one day with LEFO and about 1.5 days with random demand.

Consequently, both stock rotation scheme and customers' behavior have major impacts on the performance of the investigated supply chain. Assuming that maximizing the amount of reference strawberries sold is the primary objective of decision makers, the FEFO stock rotation scheme is selected for the subsequent experiments as it performs best in each demand priority setting.

\subsection{Implementing a quality threshold at cold stores}

Available quality data enables the assignment of products of different qualities to various distribution channels in order to avoid food losses, generate additional revenue streams and maintain better overall product qualities. Therefore, the impact of implementing quality thresholds at cold stores is studied. If a product is below this limit at the cold store, it is shifted to an alternative distribution channel. Farmers can sell products directly which would decay on the way to the retail stores or sell them to the processing industry. Consequently, with a low threshold, most strawberries are shipped to the distribution center, while only strawberries with the highest qualities enter the next process step with a high one. Such a threshold potentially increases the overall quality of sold produces, reduces food losses and additionally reduces travel costs and emission by limiting food transports. Results of such an implementation at cold stores are shown in Fig. 6 considering a FEFO stock rotation scheme. 

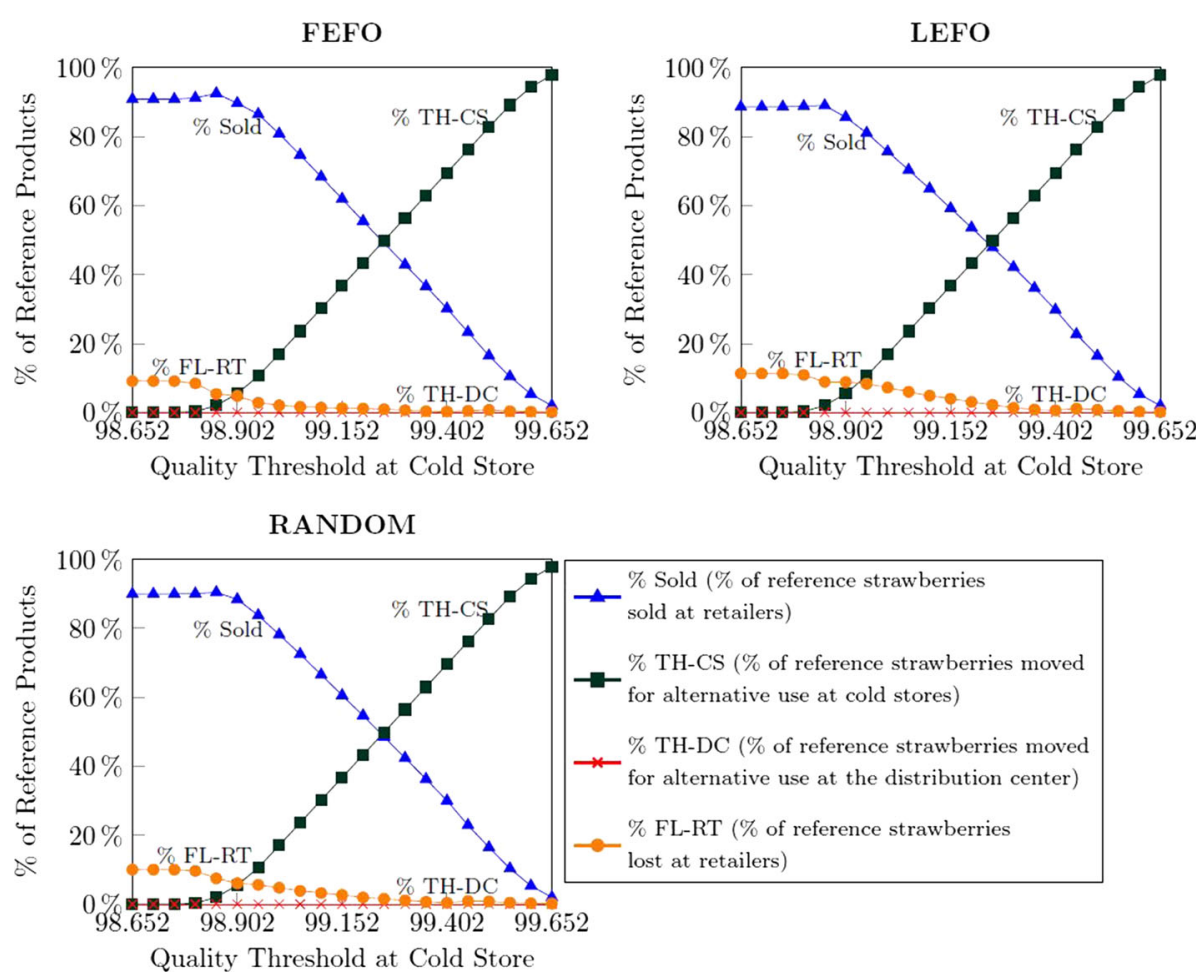

Fig. 6 Impact of implementing a quality threshold at cold stores considering a FEFO stock rotation scheme

Impacts of a quality threshold at the cold stores are analyzed with respect to the three studied demand priorities.

In each setting, no food losses at the distribution center (\% TH_DC) occur. The more strawberries are removed from the process at the cold store and used alternatively, i.e., higher quality thresholds are implemented, the less strawberries are lost at the retail stores $(\%$ FL_RT). This even results in a slight increase in the amount of reference strawberries sold (\% Sold) as produces with longer remaining shelf lives are shipped to the stores. Nevertheless, if the threshold is set too high, sales at the retail stores plummet as too few strawberries are shipped to the distribution center. Considering a quality threshold of $99.002 \%$ at cold stores, nearly $18 \%$ of all reference strawberries can be sold via alternative distribution channels at the cold store. Nevertheless, the impact of such a threshold on retail stores varies substantially depending on the considered demand priority. Under a FEFO demand setting, $80 \%$ of the strawberries are sold at the retail stores while merely $2 \%$ are lost. In contrast, if demand follows a LEFO priority, only $75 \%$ are sold while $7 \%$ are lost and a random demand priority results in $78 \%$ of reference strawberries being sold and a loss of $4 \%$. As a result, from a supply chain perspective, customer behavior needs to be closely considered when implementing a quality threshold at cold stores as it has a major impact on operations. 

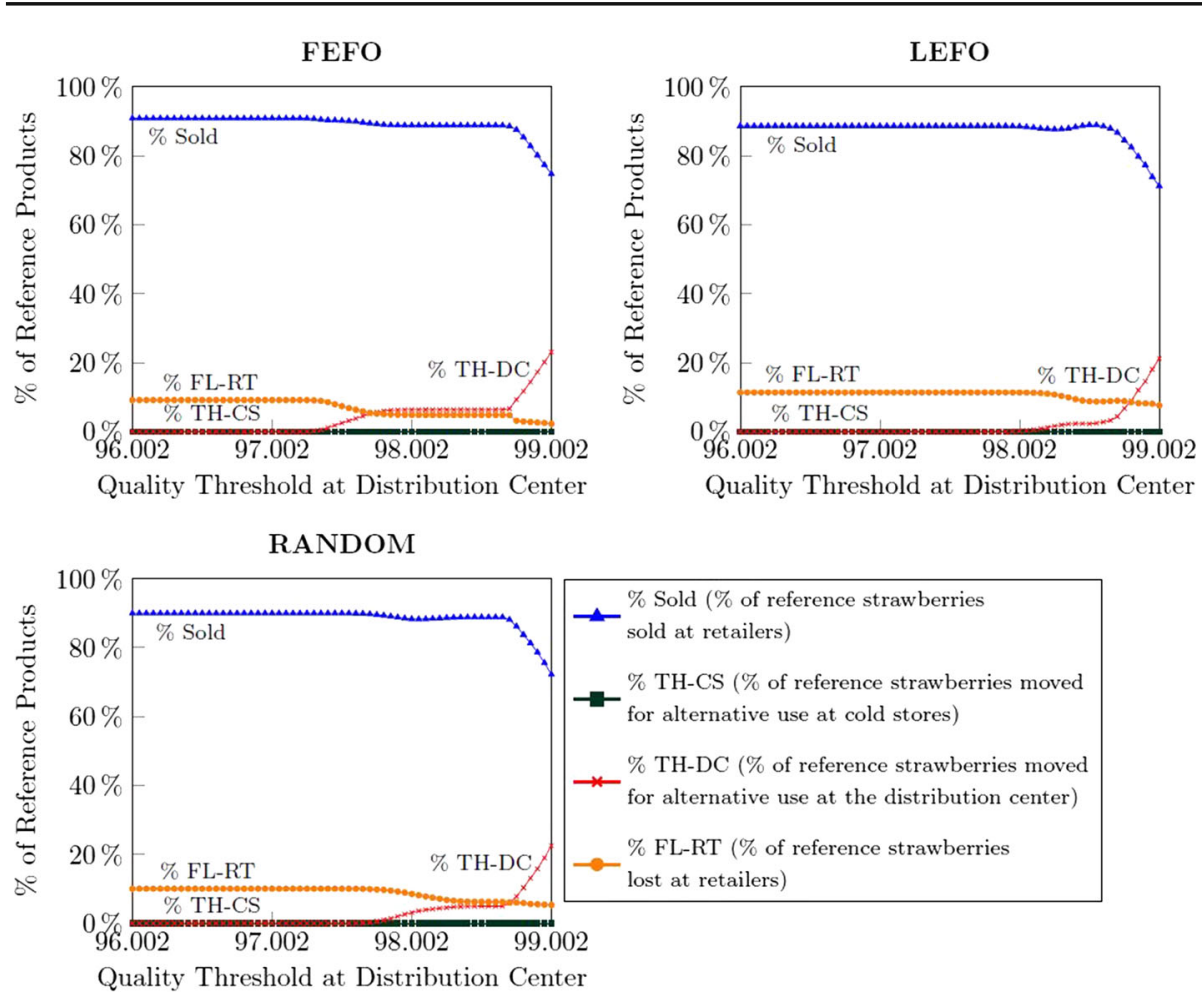

Fig. 7 Impact of implementing a quality threshold at the distribution center considering a FEFO stock rotation scheme

\subsection{Implementing a quality threshold at distribution centers}

Figure 7 plots the impact of facilitating quality data to implement a threshold quality at the distribution center. No limiting quality threshold at cold stores is assumed. Similarly to cold stores, the distribution center can use produces removed early from the retail supply chain to serve alternative distribution channels such as the processing industry or catering services.

Results indicate that such a threshold quality limit enables one to reduce food waste substantially by slightly reducing the amount of reference strawberries sold. Nevertheless, the demand priority is again of high importance. Assuming a FEFO demand setting, a quality threshold value between 97.802 and 98.652 at the distribution center reduces food losses by $4 \%$, while allowing the distribution center to switch $6 \%$ to alternative distribution channel at a reduction in sold produces at the retailer by $2 \%$. A higher quality threshold, where food losses further decrease slightly, results in a sharp drop in sales at retailers as too few strawberries are available for shipment. If the best qualities are in demand (LEFO), potentials to use products for alternative usage at the distribution center are limited, while a random demand priority again shows medium benefits. 
Table 5 Optimal strategies considering various decision maker objectives under a FEFO stock rotation scheme

\begin{tabular}{|c|c|c|c|c|c|c|}
\hline & TH-CS ${ }^{\mathrm{a}}$ & TH-DC ${ }^{b}$ & $\%$ Sold $^{\mathrm{c}}$ & $\% \mathrm{TH}-\mathrm{CS}^{\mathrm{d}}$ & $\% \mathrm{TH}-\mathrm{DC}$ & $\%$ FL-RT $^{f}$ \\
\hline \multicolumn{7}{|l|}{ FEFO } \\
\hline $\max \%$ sold & 98.852 & - & 92.56 & 2.04 & 0.00 & 5.40 \\
\hline \multicolumn{7}{|l|}{$\geq 90 \%$ sold } \\
\hline $\max \% \mathrm{TH}-\mathrm{CS}$ & 98.852 & - & 92.56 & 2.04 & 0.00 & 5.40 \\
\hline $\max \% \mathrm{TH}-\mathrm{DC}$ & 98.802 & 97.652 & 90.06 & 0.27 & 3.84 & 5.84 \\
\hline $\min \%$ FL-RT & 98.852 & 97.902 & 90.40 & 2.04 & 2.72 & 4.85 \\
\hline \multicolumn{7}{|l|}{$\geq 87.5 \%$ sold } \\
\hline $\max \% \mathrm{TH}-\mathrm{CS}$ & 98.902 & - & 89.73 & 5.48 & 0.00 & 4.79 \\
\hline $\max \% \mathrm{TH}-\mathrm{DC}$ & 98.652 & 98.752 & 87.60 & 0.00 & 9.27 & 3.13 \\
\hline $\min \%$ FL-RT & 98.852 & 98.752 & 87.61 & 2.04 & 7.24 & 3.11 \\
\hline \multicolumn{7}{|l|}{$\geq 85 \%$ sold } \\
\hline $\max \% \mathrm{TH}-\mathrm{CS}$ & 98.952 & - & 86.53 & 10.60 & 0.00 & 2.87 \\
\hline $\max \% \mathrm{TH}-\mathrm{DC}$ & 98.652 & 98.802 & 85.39 & 0.00 & 11.71 & 2.90 \\
\hline $\min \%$ FL-RT & 98.952 & 98.752 & 85.13 & 10.60 & 1.57 & 2.70 \\
\hline \multicolumn{7}{|l|}{$L E F O$} \\
\hline $\max \%$ sold & 98.852 & - & 89.06 & 2.04 & 0.00 & 8.90 \\
\hline \multicolumn{7}{|l|}{$\geq 90 \%$ sold } \\
\hline $\max \% \mathrm{TH}-\mathrm{CS}$ & - & - & - & - & - & - \\
\hline $\max \% \mathrm{TH}-\mathrm{DC}$ & - & - & - & - & - & - \\
\hline $\min \% \mathrm{FL}-\mathrm{RT}$ & - & - & - & - & - & - \\
\hline \multicolumn{7}{|l|}{$\geq 87.5 \%$ sold } \\
\hline $\max \% \mathrm{TH}-\mathrm{CS}$ & 98.852 & - & 89.06 & 2.04 & 0.00 & 8.90 \\
\hline $\max \% \mathrm{TH}-\mathrm{DC}$ & 98.652 & 98.652 & 88.00 & 0.00 & 3.20 & 8.80 \\
\hline $\min \%$ FL-RT & 98.652 & 98.552 & 88.93 & 0.00 & 2.40 & 8.68 \\
\hline \multicolumn{7}{|l|}{$\geq 85 \%$ sold } \\
\hline $\max \% \mathrm{TH}-\mathrm{CS}$ & 98.902 & - & 85.66 & 5.48 & 0.00 & 8.86 \\
\hline $\max \% \mathrm{TH}-\mathrm{DC}$ & 98.652 & 98.702 & 86.75 & 0.00 & 4.32 & 8.93 \\
\hline $\min \%$ FL-RT & 98.652 & 98.552 & 88.93 & 0.00 & 2.40 & 8.68 \\
\hline \multicolumn{7}{|l|}{ RANDOM } \\
\hline $\max \%$ sold & 98.852 & - & 90.46 & 2.04 & 0.00 & 7.50 \\
\hline \multicolumn{7}{|l|}{$\geq 90 \%$ sold } \\
\hline $\max \% \mathrm{TH}-\mathrm{CS}$ & 98.852 & - & 90.46 & 2.04 & 0.00 & 7.50 \\
\hline $\max \% \mathrm{TH}-\mathrm{DC}$ & 98.852 & 98.052 & 90.14 & 2.04 & 0.44 & 7.39 \\
\hline $\min \%$ FL-RT & 98.852 & 98.052 & 90.14 & 26.04 & 0.44 & 7.39 \\
\hline \multicolumn{7}{|l|}{$\geq 87.5 \%$ sold } \\
\hline $\max \% \mathrm{TH}-\mathrm{CS}$ & 98.902 & - & 88.42 & 5.48 & 0.00 & 6.10 \\
\hline $\max \% \mathrm{TH}-\mathrm{DC}$ & 98.652 & 98.702 & 88.12 & 0.00 & 5.82 & 6.06 \\
\hline $\min \% \mathrm{FL}-\mathrm{RT}$ & 98.852 & 98.702 & 87.91 & 2.04 & 4.01 & 6.05 \\
\hline
\end{tabular}


Table 5 continued

\begin{tabular}{|c|c|c|c|c|c|c|}
\hline & $\mathrm{TH}-\mathrm{CS}^{\mathrm{a}}$ & TH-DC ${ }^{b}$ & $\%$ Sold $^{\mathrm{c}}$ & $\% \mathrm{TH}-\mathrm{CS}^{\mathrm{d}}$ & $\% \mathrm{TH}-\mathrm{DC} \mathrm{e}^{\mathrm{e}}$ & $\%$ FL-RT $^{f}$ \\
\hline \multicolumn{7}{|l|}{$\geq 85 \%$ sold } \\
\hline $\max \% \mathrm{TH}-\mathrm{CS}$ & 98.902 & - & 88.42 & 5.48 & 0.00 & 6.10 \\
\hline $\max \% \mathrm{TH}-\mathrm{DC}$ & 98.652 & 98.752 & 86.19 & 0.00 & 7.79 & 6.02 \\
\hline $\min \% \mathrm{FL}-\mathrm{RT}$ & 98.902 & 98.752 & 85.71 & 5.48 & 2.86 & 5.95 \\
\hline
\end{tabular}

${ }^{\text {a } Q u a l i t y ~ t h r e s h o l d ~ a t ~ c o l d ~ s t o r e ~}$

${ }^{\mathrm{b}}$ Quality threshold at distribution center

$\mathrm{c} \%$ of reference strawberries sold at retailers

$\mathrm{d} \%$ of reference strawberries moved for alternative use at cold stores

e $\%$ of reference strawberries moved for alternative use at distribution center

$\mathrm{f} \%$ of reference strawberries lost at retailers

\subsection{Implementing multiple quality thresholds}

Table 5 shows the impact if both thresholds at cold stores and the distribution center are jointly implemented. Various decision maker objectives are investigated considering a minimum amount of reference strawberries being sold at the retail stores. Results are based on a complete enumeration and the stock rotation scheme is again set to FEFO. As can be seen, under a FEFO demand priority, the most strawberries can be sold and the lowest food losses can be achieved whereas LEFO produces most food losses and random performs in-between. If farmers want to maximize goods for alternative use, no berries are rejected at the distribution center and vice versa. Overall, the most strawberries can be sold if a quality threshold at cold stores of 98.852 (5.7 days) and no further quality threshold at the distribution center are set. To reduce food losses, at both stages strawberries should be alternatively used if below a minimum threshold quality.

Figure 8 visualizes the impacts of quality thresholds and customer demands on the performance of the supply chain. Two different strategies are compared: (i) no alternative use, where the percentage of sold reference strawberries at retailers count $100 \%$, and (ii) alternative use at cold stores and at the distribution center, where the percentage of sold strawberries at retailers count $100 \%$ and the percentage of alternatively used berries at the cold stores $75 \%$ and $50 \%$ at the distribution center. In both settings, no value for food lost at retailers is generated.

The yellow areas show the range of the maximum objective values. As can be seen, no alternative uses need low thresholds, as only sold products count. Consequently, it is beneficial to ship as many strawberries as possible to retailers. With alternatively used products, the implementation of thresholds improves the overall objective. For the investigated setting, implementing a quality threshold at cold stores is beneficial. A threshold at the distribution center has only marginal impacts on the objective value under FEFO demand priority, whereas under LEFO and RANDOM, it provides one the option to improve operations if no threshold at cold stores can be implemented. This might be of special interest as implementing realtime food quality data may be considerably easier to achieve at a single distribution center compared to multiple cold stores at the individual farms. Consequently, implementing quality data enables one to strengthen supply chain performance by enabling efficient alternative use of products, however, requires a close consideration of customers' demand priorities and a close integration of all members of the supply chain. 


\section{FEFO}

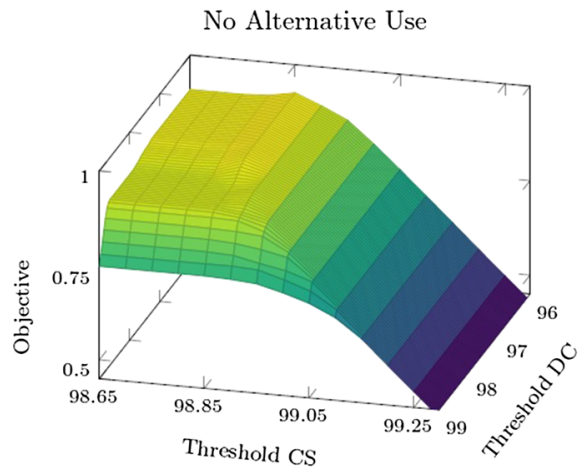

Alternative Use ( $75 \%$ of value at CS; $50 \%$ at DC)

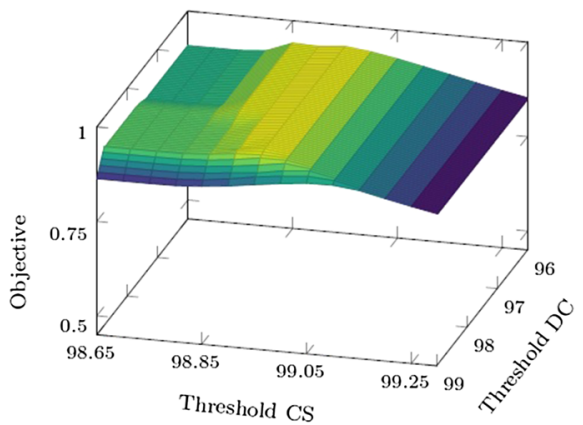

LEFO

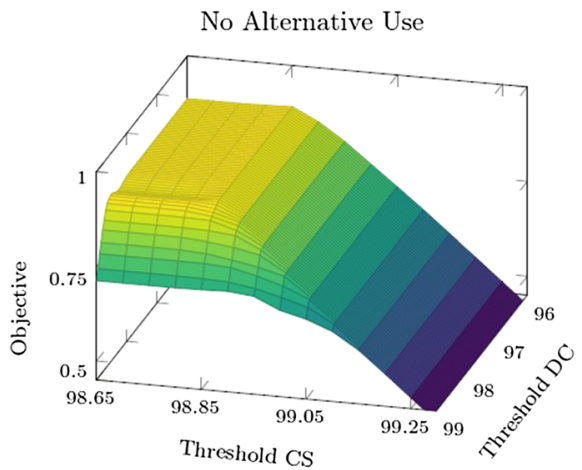

Alternative Use ( $75 \%$ of value at $\mathrm{CS} ; 50 \%$ at DC)

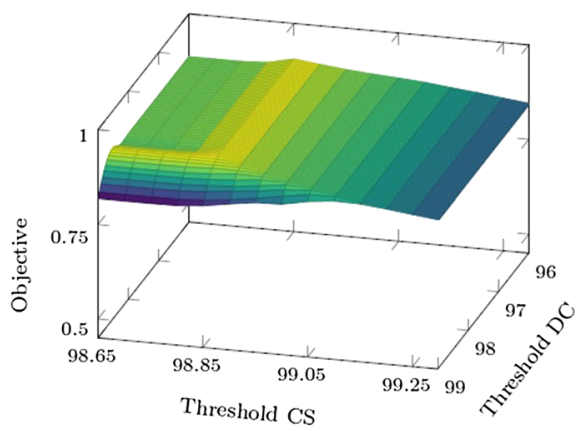

\section{RANDOM}

No Alternative Use

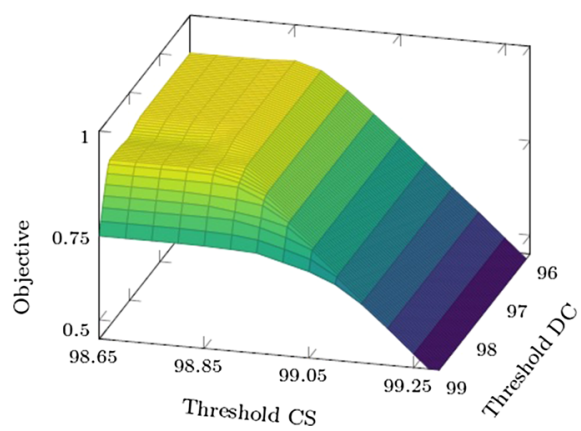

Alternative Use ( $75 \%$ of value at CS; $50 \%$ at DC)

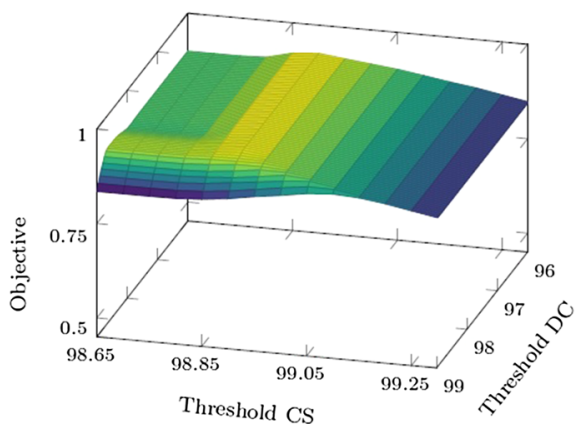

Fig. 8 Comparison of alternative use strategies considering a FEFO stock rotation scheme

\section{Conclusions}

This work provided insights on implications of facilitating real-time quality data in fresh fruit supply chain operations. It analyzed the knowledge of quality information and its impacts on chain performance by studying benefits of various stock rotation schemes and quality thresholds implemented at cold stores and distribution centers. 
Results of a study of a regional organic strawberry supply chain show that real-time information of product quality can improve chain performance at various points. It enables decision support on which product should be shipped to the next process step or better be sold via other distribution channels with shorter handling durations. These decisions can generate additional income, lower transportation expenses and further reduce emissions, food losses as well as waste disposal costs. Nevertheless, the customers' demand behavior has large impacts on achieved benefits of such integrations. Even the best stock rotation scheme and optimal quality thresholds can only achieve slight improvements if the customers always choose goods with high qualities first. Furthermore, from a supply chain perspective, the sharing of achieved overall benefits among the different actors is of importance to enable successful implementations. For instance, implementing minimum quality thresholds at cold stores and distribution centers in most cases hurt the performance of retailers requiring compensations.

Future work concentrates on the simultaneous implementation of various products types with different deterioration characteristics in the system. This requires decisions on optimal storage conditions resulting in complex trade-offs between the individual product classes. The joint storage of different produces is challenging, particularly when aiming to maintain high qualities and low food losses. As shipping volumes within organic food supply chains are often substantially lower than of conventionally produced fruits or vegetables, tailored DSSs are required to consider joint storage and transport settings present in this emerging industry.

Acknowledgements Open access funding provided by University of Natural Resources and Life Sciences Vienna (BOKU). This work was financially supported by the program Mobility of the Future (Grant Number 859148), an initiative of the Austrian Ministry for Transport, Innovation and Technology. We further like to thank our project partner BIO AUSTRIA, particularly Susanne Maier, Claus Holler and Helmut StachowetzAxmann, for providing us with data and feedback.

Open Access This article is distributed under the terms of the Creative Commons Attribution 4.0 International License (http://creativecommons.org/licenses/by/4.0/), which permits unrestricted use, distribution, and reproduction in any medium, provided you give appropriate credit to the original author(s) and the source, provide a link to the Creative Commons license, and indicate if changes were made.

\section{References}

Ahumada, O., \& Villalobos, J. R. (2009). Application of planning models in the agri-food supply chain: A review. European Journal of Operational Research, 196(1), 1-20.

AnyLogic. (2018). Anylogic-Multimethod simulation software. Retrieved June 26, 2018, from http://www. anylogic.com/.

Ayala-Zavala, J., Wang, S. Y., Wang, C. Y., \& González-Aguilar, G. A. (2004). Effect of storage temperatures on antioxidant capacity and aroma compounds in strawberry fruit. LWT - Food Science and Technology, 37(7), 687-695.

Badia-Melis, R., Mc Carthy, U., Ruiz-Garcia, L., Garia-Hierro, J., \& Robla Villalba, J. (2018). New trends in cold chain monitoring applications-A review. Food Control, 86, 170-182.

Bio Austria. (2018a). Bio-Erdbeeren [Organic Strawberries]. Retrieved March 05, 2018, from http://www. bio-austria.at/download/lebensmittel-der-woche-bio-erdbeeren-frisch-voller-aroma/.

Bio Austria. (2018b). Biomap. Retrieved March 19, 2018, from http://www.bio-austria.at/biomap.

BMNT. (2016). Grüner Bericht 2016 - Bericht über die Situation der österreichischen Land- und Forstwirtschaft [green report 2016]. Austrian Ministry for Sustainability and Tourism, Vienna, Austria. Retrieved February 22, 2018, from https://gruenerbericht.at/cm4/jdownload/download/2-gr-berichtterreich/1650-gb2016.

Borodin, V., Bourtembourg, J., Hnaien, F., \& Labadie, N. (2016). Handling uncertainty in agricultural supply chain management: A state of the art. European Journal of Operational Research, 254(2), 348-359.

Broekmeulen, R. A. (1998). Operations management of distribution centers for vegetables and fruits. International Transactions in Operational Research, 5(6), 501-508. 
Cancela, H., Higgins, A., Pagès-Bernaus, A., \& Plà-Aragonès, L. M. (2019). Prologue-BigData and DSS in agriculture. Computers and Electronics in Agriculture, 161, 1-3.

Corbo, M. R., Del Nobile, M. A., \& Sinigaglia, M. (2006). A novel approach for calculating shelf life of minimally processed vegetables. International Journal of Food Microbiology, 106(1), 69-73.

de Keizer, M., Akkerman, R., Grunow, M., Bloemhof, J. M., Haijema, R., \& van der Vorst, J. (2017). Logistics network design for perishable products with heterogeneous quality decay. European Journal of Operational Research, 262, 535-549.

Díaz-Pérez, J. C., Bautista, S., Villanueva, R., \& López-Gómez, R. (2003). Modeling the ripening of sapote mamey [Pouteria sapota (Jacq.) H.E. Moore and Stearn] fruit at various temperatures. Postharvest Biology and Technology, 28(1), 199-202.

Fikar, C. (2018). A decision support system to investigate food losses in e-grocery deliveries. Computers \& Industrial Engineering, 117, 282-290.

Fredriksson, A., \& Liljestrand, K. (2015). Capturing food logistics: A literature review and research agenda. International Journal of Logistics Research and Applications, 18(1), 16-34.

Giménez, A., Ares, F., \& Ares, G. (2012). Sensory shelf-life estimation: A review of current methodological approaches. Food Research International, 49(1), 311-325.

Grunow, M., \& Piramuthu, S. (2013). RFID in highly perishable food supply chains-Remaining shelf life to supplant expiry date? International Journal of Production Economics, 146(2), 717-727.

Haijema, R., \& Minner, S. (2016). Stock-level dependent ordering of perishables: A comparison of hybrid base-stock and constant order policies. International Journal of Production Economics, 181, Part A, $215-225$.

Hertog, M. (2002). The impact of biological variation on postharvest population dynamics. Postharvest Biology and Technology, 26(3), 253-263.

Hertog, M., Boerrigter, H., van den Boogaard, G., Tijskens, L., \& van Schaik, A. (1999). Predicting keeping quality of strawberries (cv. 'Elsanta') packed under modified atmospheres: An integrated model approach. Postharvest Biology and Technology, 15(1), 1-12.

Hertog, M., Lammertyn, J., De Ketelaere, B., Scheerlinck, N., \& Nicolaï, B. M. (2007). Managing quality variance in the postharvest food chain. Trends in Food Science and Technology, 18(6), 320-332.

Hertog, M., Lammertyn, J., Desmet, M., Scheerlinck, N., \& Nicolai, B. M. (2004). The impact of biological variation on postharvest behaviour of tomato fruit. Postharvest Biology and Technology, 34(3), 271-284.

Hertog, M., \& Tijskens, L. M. M. (1998). Modelling modified atmosphere packaging of perishable produce: Keeping quality at dynamic conditions. Acta Alimentaria, 27, 53-62.

Hertog, M., Uysal, I., McCarthy, U., Verlinden, B. M., \& Nicolai, B. M. (2014). Shelf life modelling for firstexpired-first-out warehouse management. Philosophical Transactions of the Royal Society A, 372(2017), 20130306.

Hertog, M., Vollebregt, M., Unzueta, I., Hoofman, R., \& Lammertyn, J. (2015). From sensor output to improved product quality. Acta Horticulturae, 1091, 165-173.

Higgins, A. J., Miller, C. J., Archer, A. A., Ton, T., Fletcher, C. S., \& McAllister, R. R. J. (2010). Challenges of operations research practice in agricultural value chains. Journal of the Operational Research Society, 61(6), 964-973.

Jedermann, R., Nicometo, M., Uysal, I., \& Lang, W. (2014). Reducing food losses by intelligent food logistics. Philosophical Transactions of the Royal Society A, 372(2017), 20130302.

Khorshidi, J., Tabatabeai, M. F., \& Ahmadi, F. M. (2010). Storage temperature effects on the postharvest quality of apple (Malus domestica Borkh. cv.Red Delicious). New York Science Journal, 3(3), 67-70.

Laidler, K. J. (1984). The development of the Arrhenius equation. Journal of Chemical Education, 61(6), 494.

Leithner, M., \& Fikar, C. (2018). Simulating fresh food supply chains by integrating product quality. In N. Kliewer, J. Ehmke, \& R. Borndörfer (Eds.), Operations research proceedings 2017 (pp. 671-676). Berlin: Springer.

Li, C., \& Kader, A. A. (1989). Residual effects of controlled atmospheres on postharvest physiology and quality of strawberries. Journal of the American Society for Horticultural Science, 114, 629-634.

Li, D., \& Wang, X. (2017). Dynamic supply chain decisions based on networked sensor data: an application in the chilled food retail chain. International Journal of Production Research, 55(17), 5127-5141.

Long, Q., \& Zhang, W. (2014). An integrated framework for agent based inventory-production-transportation modeling and distributed simulation of supply chains. Information Sciences, 277, 567-581.

Lundqvist, J., de Fraiture, C., \& Model, D. (2008). Saving water: From field to fork-Curbing losses and wastage in the food chain. Technical report, SIWI Policy Brief, Stockholm.

Nunes, M. C., Nicometo, M., Emond, J. P., Melis, R. B., \& Uysal, I. (2014). Improvement in fresh fruit and vegetable logistics quality: Berry logistics field studies. Philosophical Transactions of the Royal Society A, 372(2017), 20130307. 
Nunes, M. C. N., \& Emond, J. P. (2003). Quality of strawberries as affected by temperature abuse during ground, in-flight and retail handling operations. Acta Horticulturae, 604, 239-246.

OpenStreetMap. (2018). Openstreetmap. Retrieved June 26, 2018, from www.openstreetmap.org/.

Parfitt, J., Barthel, M., \& Macnaughton, S. (2010). Food waste within food supply chains: Quantification and potential for change to 2050. Philosophical Transactions of the Royal Society B: Biological Sciences, 365(1554), 3065-3081.

Raut, R. D., Gardas, B. B., Narwane, V. S., \& Narkhede, B. E. (2019). Improvement in the food losses in fruits and vegetable supply chain-A perspective of cold third-party logistics approach. Operations Research Perspectives, 6(100), 117.

Reynolds, C. J., Buckley, J. D., Weinstein, P., \& Boland, J. (2014). Are the dietary guidelines for meat, fat, fruit and vegetable consumption appropriate for environmental sustainability? A review of the literature. Nutrients, 6(6), 2251-2265.

Rong, A., Akkerman, R., \& Grunow, M. (2011). An optimization approach for managing fresh food quality throughout the supply chain. International Journal of Production Economics, 131(1), 421-429.

Rupnik, R., Kukar, M., Vračar, P., Košir, D., Pevec, D., \& Bosnić, Z. (2019). AgroDSS: A decision support system for agriculture and farming. Computers and Electronics in Agriculture, 161, 260-271.

Schneider, F., Lebersorger, S., Bernholt, B., \& Zehetgruber, B. (2014). Food Waste und Landwirtschaft Orientierende Erhebung von Verlusten an Lebensmitteln in der Landwirtschaft - Aufkommen, Zusammensetzung und Gründe [Food Waste and Agriculture]. Endbericht im Auftrag des Bundesministeriums für Land- und Forstwirtschaft, Umwelt und Wasserwirtschaft, Abteilung VI/6.

Schouten, R. E., Tijskens, L., \& van Kooten, O. (2002). Predicting keeping quality of batches of cucumber fruit based on a physiological mechanism. Postharvest Biology and Technology, 26(2), 209-220.

Sloof, M., Tijskens, L., \& Wilkinson, E. (1996). Concepts for modelling the quality of perishable products. Trends in Food Science \& Technology, 7(5), 165-171.

Song, B. D., \& Ko, Y. D. (2016). A vehicle routing problem of both refrigerated- and general-type vehicles for perishable food products delivery. Journal of Food Engineering, 169(Supplement C), 61-71.

Soto-Silva, W. E., Nadal-Roig, E., González-Araya, M. C., \& Pla-Aragones, L. M. (2016). Operational research models applied to the fresh fruit supply chain. European Journal of Operational Research, 251(2), 345355.

Soto-Silva, W. E., Gonzàlez-Araya, M. C., Oliva-Fernàndez, M. A., \& Plà-Aragonès, L. M. (2017). Optimizing fresh food logistics for processing: Application for a large Chilean apple supply chain. Computers and Electronics in Agriculture, 136, 42-57.

Statistik Austria. (2013). Registerbasierte Statistiken - Demographie (RS). Registerzählung 2011 [Austrian population statistics 2011]. Technical Report Schnellbericht 10.7, Wien, Austria, Vienna. Retrieved January 31, 2018, fromhttps://www.statistik.at/web_de/statistiken/menschen_und_ gesellschaft/bevoelkerung/index.html.

Statistik Austria. (2017). Versorgungsbilanz für Obst 2010/11 bis 2015/16 [supply balance of fruits $2010 / 11$ 2015/16]. Austria, Vienna. Retrieved January 31, 2018, from http://www.statistik.at/web_de/statistiken/ wirtschaft/land_und_forstwirtschaft/preise_bilanzen/versorgungsbilanzen/index.html.

Tako, A. A., \& Robinson, S. (2012). The application of discrete event simulation and system dynamics in the logistics and supply chain context. Decision Support Systems, 52(4), 802-815.

Teller, C., Holweg, C., Reiner, G., \& Kotzap, H. (2018). Retail store operations and food waste. Journal of Cleaner Production, 185, 981-997.

Tijskens, L. M. M., \& Polderdijk, J. J. (1996). A generic model for keeping quality of vegetable produce during storage and distribution. Agricultural Systems, 51(4), 431-452.

United Nations. (2014). World urbanization prospects: The 2014 revision. Technical report, Department of Economic and Social Affairs, New York. Retrieved September 21, 2017, from https://esa.un.org/unpd/ wup/publications/files/wup2014-highlights.pdf.

van der Vorst, J., Tromp, S. O., \& van der Zee, D. J. (2009). Simulation modelling for food supply chain redesign; Integrated decision making on product quality, sustainability and logistics. International Journal of Production Research, 47(23), 6611-6631.

van der Vorst, J. G. A. J., van Kooten, O., \& Luning, P. A. (2011). Towards a diagnostic instrument to identify improvement opportunities for quality controlled logistics in agrifood supply chain networks. International Journal on Food System Dynamics, 2(1), 94-105.

Zhong, R. Y., Newman, S. T., Huang, G. Q., \& Lan, S. (2016). Big data for supply chain management in the service and manufacturing sectors: Challenges, opportunities, and future perspectives. Computers \& Industrial Engineering, 101, 572-591.

Publisher's Note Springer Nature remains neutral with regard to jurisdictional claims in published maps and institutional affiliations. 